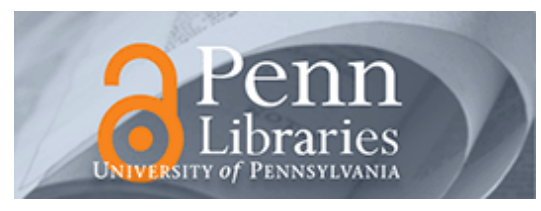

University of Pennsylvania

ScholarlyCommons

Operations, Information and Decisions Papers

Wharton Faculty Research

4-2006

\title{
An Empirical Examination of the Decision to Invest in Fulfillment Capabilities: A Study of Internet Retailers
}

Taylor Randall

Serguei Netessine

University of Pennsylvania

Nils Rudi

Follow this and additional works at: https://repository.upenn.edu/oid_papers

Part of the E-Commerce Commons, Econometrics Commons, and the Operations and Supply Chain Management Commons

\section{Recommended Citation}

Randall, T., Netessine, S., \& Rudi, N. (2006). An Empirical Examination of the Decision to Invest in Fulfillment Capabilities: A Study of Internet Retailers. Management Science, 52 (4), 567-580.

http://dx.doi.org/10.1287/mnsc.1050.0493

This paper is posted at ScholarlyCommons. https://repository.upenn.edu/oid_papers/198

For more information, please contact repository@pobox.upenn.edu. 


\title{
An Empirical Examination of the Decision to Invest in Fulfillment Capabilities: A Study of Internet Retailers
}

\author{
Abstract \\ Internet technology has allowed for a higher degree of decoupling between the information-intensive \\ sales process and the physical process of inventory management than its brick-and-mortar counterpart. \\ As a result, some Internet retailers choose to outsource inventory and back-end operations to focus on \\ the sales/marketing aspects of e-commerce. Nonetheless, many retailers keep fulfillment capabilities in- \\ house. In this paper, we identify and empirically test factors that persuade firms to integrate inventory and \\ fulfillment capabilities with virtual storefronts. Based on the extant literature and previous research in e- \\ commerce, we formulate nine theoretical predictions. We then use data from a sample of over 50 public \\ Internet retailers to test whether empirical data are consistent with these hypotheses. Finally, given the \\ strategic importance and financial magnitude of the inventory investment decision, we analyze the effect \\ of this decision on the economic success of Internet retailers during the period of study. We find that \\ there are many circumstances in which it is prudent to own fulfillment capabilities and inventory. \\ Empirical data are consistent with hypotheses that this tendency is higher for older firms selling small, \\ high-margin products, offering lower levels of product variety, and facing lower demand uncertainty. We \\ also discover that firms making inventory ownership decisions that are consistent with an empirical \\ benchmark derived from environmental and strategic factors are less likely to go bankrupt than those \\ making inconsistent inventory choices.
}

\section{Keywords}

Internet, retailing, electronic commerce, fulfillment, supply chain management, bankruptcy, econometrics, hazard model

\section{Disciplines}

E-Commerce | Econometrics | Operations and Supply Chain Management 


\title{
An Empirical Examination of the Decision to Invest in Fulfillment
}

\author{
Capabilities: A Study of Internet Retailers
}

\author{
Taylor Randall \\ David Eccles School of Business \\ University of Utah \\ Salt Lake City, Utah 84112 \\ acttr@business.utah.edu
}

\author{
Serguei Netessine \\ The Wharton School \\ University of Pennsylvania \\ Philadelphia, PA 19104 \\ netessine@wharton.upenn.edu
}

Nils Rudi

W. E. Simon School of Business University of Rochester

Rochester, NY 14627

rudi@simon.rochester.edu

July 2004, Revised February 2005

\begin{abstract}
We would like to thank Karl Ulrich, Bill Moore, Ryan Sundquist, Noah Springer, Chetan Salian, workshop participants at the University of Utah, University of Texas-Austin, Molde College, Harvard University, OM roundtable at Northwestern University, Stanford University, 2002 POMS and M\&SOM conferences for help and comments. Feedback from two referees, the Associate Editor and the Departmental Editor helped strengthen our analysis. Financial support from Wharton E-business Initiative is gratefully acknowledged.
\end{abstract}




\title{
An Empirical Examination of the Decision to Invest in Fulfillment
}

\author{
Capabilities: A Study of Internet Retailers
}

\begin{abstract}
Internet technology has allowed for a higher degree of de-coupling between the information-intensive sales process and the physical process of inventory management than its brick-and-mortar counterpart. As a result, some Internet retailers choose to outsource inventory and back-end operations in order to focus on the sales/marketing aspects of e-commerce. Nonetheless, a large number of retailers keep fulfillment capabilities in-house. In this paper we identify and test empirically factors that persuade firms to integrate inventory and fulfillment capabilities with virtual storefronts. Based on the extant literature and previous research in ecommerce, we formulate eight theoretical predictions. We then use data from a sample of over 50 public Internet retailers to test whether empirical data are consistent with these hypotheses. Finally, given the strategic importance and financial magnitude of the inventory investment decision, we analyze the effect of this decision on the ultimate financial success of Internet retailers.

We find that there are many circumstances in which it is prudent to own fulfillment capabilities and inventory. Empirical data are consistent with hypotheses that this tendency is higher for older firms selling small, high-margin products, offering lower levels of product variety and facing lower demand uncertainty. We also discover that firms making inventory ownership decisions that are consistent with theory and aligned with environmental and strategic factors are less likely to go bankrupt than those making misaligned inventory choices.
\end{abstract}




\section{Introduction}

The early Internet popular press proposed that e-commerce technology would allow decoupling of the information-intensive sales process from physical product delivery, thus permitting consumers to costlessly browse endless stocks of goods for the precise product and price they desired. The accompanying retail corollary to the consumer proposition suggested that retailers need not hold inventory; rather a retailer should only provide a virtual storefront for customers, leaving the burdensome task of inventory management to third parties who would drop-ship orders directly to consumers. ${ }^{1}$ Together these practices promised to revolutionize retailing (see Evans and Wurster [2000] and Ghosh [1998]).

However, the widespread adoption of drop-shipping fulfillment strategies and their subsequent success or failure are not readily apparent. Recent surveys report that only between 23 and 33 percent of Internet retailers rely on drop-shipping as their primary method of order fulfillment $[3,4,5]$. Most companies maintain the traditional practice of keeping fulfillment capabilities and inventories in-house. ${ }^{2}$ Furthermore, anecdotal evidence of retailers using a dropshipping strategy suggests mixed success. For example, drop-shipping retailer, Value America, declared bankruptcy in late 2000 , blaming in part the inability to deliver products to customers in a timely manner [1]. In contrast, $\mathrm{CD}$ retailer Spun.com has thrived by leveraging the inventory of the distributor, Alliance Entertainment [2]. Interestingly, a cursory examination of Internet retailers who have chosen the traditional channel by investing in inventory yields equally mixed

\footnotetext{
${ }^{1}$ Drop-shipping refers to an arrangement whereby the retailer forwards customers' orders to the wholesaler, distributor or manufacturer, who fills customer orders directly from its own inventory. Throughout this paper, we will refer to firms using this type of arrangement as using the drop-shipping approach or drop-shipping channel. ${ }^{2}$ Throughout this paper, we refer to the practice of maintaining inventories and fulfillment capabilities in-house as the traditional approach, the traditional channel or inventory ownership.
} 
results. Unable to justify the expenses associated with inventory and warehouses, grocery retailer WebVan.com declared bankruptcy in 2001. In contrast, Amazon.com invested heavily in fulfillment capabilities and at the time of writing reported profitability.

Recent analytical work identifies and analyzes factors that lead Internet retailers to appropriately adopt drop-shipping or traditional inventory strategies (see Netessine and Rudi [2004a, 2004b] and Singh et al. [2003]). Motivated by the results of these analytical studies as well as by unexplained and contradictory observations of practice, this paper provides initial empirical evidence as to the factors associated with the adoption of drop-shipping versus traditional fulfillment strategies in Internet retailing and examines the association between fulfillment strategy choice and firm performance. ${ }^{3}$

From extant theory we derive eight hypotheses linking product variety, demand uncertainty, number of retailers served by one wholesaler, firm's mean revenues, relative gross margin, firm age, product size and product obsolescence with the decision to use a traditional or drop-shipping inventory structure. Empirical tests using data from Internet retailers are consistent with several of our hypotheses. Older firms delivering smaller, high-margin products, operating with lower levels of variety and facing lower demand uncertainty tend to use the traditional channel. Conversely, newer firms with larger, low-margin products, and higher levels of variety with higher demand uncertainty tend to use the drop-shipping channel. Working from these results, we analyze how the inventory investment choice - drop-shipping versus traditional - affects firm performance. Using an empirically derived benchmark to identify outlier firms, we find statistically significant support for the argument that companies making the channel choice

\footnotetext{
${ }^{3}$ Detailed accounts of drop-shipping operations in e-commerce are well documented (see Johnson [2002a, 2002b],
} 
consistent with empirical benchmarks have a lower hazard of bankruptcy over the time period in our study.

This paper contributes to the growing body of literature on electronic commerce by demonstrating the strategic importance of inventory and fulfillment capabilities (i.e., physical assets) in the e-commerce world. While issues of pricing, customer acquisition and distribution of information goods on the Internet have been addressed both theoretically and empirically, decisions related to fulfillment have received attention mostly from a modeling point of view. Johnson and Whang [2002] and Simchi-Levi et al. [2004] provide an overview of emerging research that includes theoretical papers, cases and a few empirical studies (none of which examines the fulfillment or inventory ownership aspects of e-commerce). The only exception we are aware of is the paper by Dinlersozy and $\mathrm{Li}$ [2003] that empirically investigates the shipping policies of Internet retailers (without focusing on the ownership of inventory and fulfillment capabilities).

More narrowly, this paper contributes to current work in drop-shipping (see Scheel [1990], Netessine and Rudi [2004a, 2004b] and Singh et al. [2003]) by providing an empirical examination of when drop-shipping is a valuable and viable method of order fulfillment. More generally, our work contributes to the empirical literature linking a firm's performance with its operational strategy (see Hendricks and Singhal [2003] for an examination of the impact of supply chain glitches on a company's financial performance, Lieberman and Dhawan [2000] for an explanation of heterogeneity in automotive manufacturers' performance and Roth and Jackson [1995] for a study of the impact of operations capabilities on a service firms' strategic

Randall et al. [2002]), but do not test developed theory pertaining to the adoption of drop-shipping. 
behavior). In particular, this research provides empirical support to the literature in operations strategy claiming that favorable economic outcomes for firms are a function of the fit between a chosen strategy and the competitive environment (Randall and Ulrich [2001]).

The rest of the paper is organized as follows. In section 2, we derive eight hypotheses. In Section 3, we describe our data. The results of hypotheses tests are reported in Section 4. In Section 5, we examine whether the decision to invest in fulfillment capabilities is associated with firm performance. We discuss the implications of our results and the limitations of our study in Section 6.

\section{Development of Hypotheses}

In this section we propose eight theoretical factors that mitigate economic tradeoffs and influence the decision to couple the ownership of fulfillment capabilities with an Internet storefront. These factors are: variety of products offered, demand uncertainty, number of retailers in the channel, firm's mean revenue, relative gross margin, firm's age, product size/weight and product obsolescence. Predictions for the influence of these factors upon the inventory fulfillment strategy are obtained using results from the operations literature as well as

results from our earlier work in Netessine and Rudi [2004b]. In the Appendix, we develop a stylized analytical model that summarizes existing research and can be used to derive predictions regarding the impact of product and environmental characteristics on the decision regarding inventory ownership. This model incorporates many parameters of the environment in which Internet retailers operate and is based on more elaborate models of Netessine and Rudi [2004b] and Singh et al. [2003], which can be consulted for details. 
In what follows, we assume that the Internet retailer starts by selecting the nature of products it offers to customers since this fundamental choice typically precedes any operational/marketing decisions. This choice leads to a tactical decision environment in which the product gross margin, product characteristics, demand uncertainty and supplier base are relatively constrained given the decision about product choice. Thereafter, the retailer makes the operational decision of which distribution channel structure to use. Note that if the traditional channel is chosen, the retailer then selects a specific level of product variety and makes multiple inventory replenishment decisions for each product within the variety. If, however, the retailer selects the drop-shipping channel, it is the wholesaler that makes detailed product variety and inventory management decisions.

\subsection{Product Variety}

Research in marketing and operations has long recognized that offering a wider variety of products increases a firm's demand (see Ramdas [2003]). At the same time, additional operational costs associated with higher product variety are also well documented (see Randall and Ulrich [2001] and van Ryzin and Mahajan [1999]). Note further that in the drop-shipping channel, the higher cost of product variety is mitigated by the effect of risk pooling (see Eppen [1979] for cornerstone work on risk pooling): since the wholesaler is stocking inventory for multiple retailers, demand uncertainty is reduced due to imperfect correlation among products. In practice wholesalers serve many (sometimes thousands of) retailers so we expect the dropshipping channel to benefit from economies of scale. Therefore, the mismatch between demand and supply due to product variety will be lower in the drop-shipping channel and it will thus be cost-effective to carry a larger variety of products. In particular, Singh et al. [2003] demonstrate 
that, due to this effect, the wholesaler under drop-shipping typically selects larger product variety than does the retailer in the traditional channel, which leads to our first hypothesis.

Hypothesis 1. Inventory ownership will be negatively associated with product variety.

\subsection{Demand Uncertainty}

The traditional operations management literature provides ample evidence that higher demand variability (captured by the standard deviation of demand) leads to higher supply chain costs due to the increasing mismatch between demand and supply (see Silver et al. [1998], Ramdas [2003]). Starting with the seminal work of Eppen [1979], research on risk pooling has demonstrated that a strategy of pooling inventory into one location mitigates this harmful effect. A variety of strategies related to risk pooling have been proposed in the operations literature including component commonality and variety postponement (Cachon and Terwiesch [2004]), but all have the basic idea of risk pooling as an underlying concept. Similarly, in the dropshipping supply chain, the wholesaler is able to mitigate the detrimental effects of demand variability due to the benefits of risk pooling: instead of stocking inventory at thousands of retail locations, it is stocked in one - the wholesaler's - location, which allows pooling of demand and reduction in overall variability. Hence, in line with other research on inventory management, we predict the following:

Hypothesis 2. Inventory ownership will be negatively associated with demand uncertainty.

\subsection{Number of Retailers}

The benefits of risk pooling in the drop-shipping channel mitigate both the cost of product variety and the cost of demand uncertainty. However, the extent of these benefits depends on the 
number of retailers that each wholesaler ${ }^{4}$ serves: the higher the number, the lower the effective uncertainty that the wholesaler ultimately faces. In the traditional channel, on the other hand, there are no benefits of inventory pooling for retailers. Hence, all else equal, we expect that a larger number of retailers in the channel should make the drop-shipping arrangement more attractive to retailers. Another justification for this hypothesis comes from accounting for the benefits of operational pooling rather than inventory pooling. For example, the wholesaler serving more retailers should be able to capitalize on the economies of scale to reduce the cost of order processing, picking and packing. These savings would ultimately be passed on to the retailers, making drop-shipping more attractive.

In practice, a retailer often buys the same product from multiple wholesalers. Since our goal is to measure the extent of the benefits of risk pooling, the relevant variable to consider is the ratio of retailers to wholesalers leading to the following hypothesis ${ }^{5}$ :

Hypothesis 3. Inventory ownership will be negatively associated with the ratio of the number of retailers to the wholesalers.

\subsection{Firm's ability to recoup fixed operational costs}

Retailing on the Internet necessitates development of fulfillment capabilities and back-end information systems. This, in turn, requires significant fixed cost investment. If the firm elects to rely on drop-shipping, these fixed costs primarily include investment into information technology that is needed to integrate the back-end fulfillment system with the wholesaler in

\footnotetext{
${ }^{4}$ Throughout this paper we assume that the wholesaler is the one who drop-ships products at retailers' requests. In practice, products can be drop-shipped by manufacturers and even by other retailers. However, this is a reasonable simplification since, as our interactions with executives indicate, a majority of products are drop-shipped by the wholesalers.
} 
order to obtain real-time inventory and pricing information. On the other hand, if the firm selects to own inventory, most of these fixed costs will be spent on physical fulfillment capabilities (such as warehouses, shipping/packing equipment, personnel). Reports from Internet retailers indicate that the fixed investment in inventory and warehousing capabilities can range from $\$ 8$ million (Spun.com $-\mathrm{CD}$ retailing) to $\$ 100$ million (Webvan - grocery retailing). Back-end software systems are expensive as well: Amazon.com reports that these costs have historically accounted for 10-15\% of the cost of goods sold (see Ghemawat and Baird [1998]). We believe that total fixed costs are much higher if the Internet retailer decides to own inventory and warehouses, which was independently confirmed by many executives with whom we communicated as well as by numerous trade publications citing the huge investment costs incurred by retailers utilizing traditional supply chains.

In order to accumulate the cash that is necessary for investment into fulfillment capabilities, a firm needs a steady stream of revenues: the larger the stream, the easier it becomes to recoup the investment ${ }^{6}$. A large stream of revenues justifies fixed cost investments, allowing firms to capture a margin typically given away to partners that own inventory and provide fulfillment (Scheel [1990] cites that drop-shipping reduces margins by 10-15\%). This reasoning suggests that larger firms (in terms of having larger revenue streams) will be more willing to take on fixed cost investments because they will accumulate cash more quickly, while smaller firms will choose to drop-ship in order to avoid large fixed costs. Moreover, similar to Hypothesis 3, this proposition is further supported if we consider operational pooling: larger firms can leverage

\footnotetext{
${ }^{5}$ Note also that this ratio can be thought of as a proxy for the retailer's market power relative to the wholesaler. One would expect that higher market power should allow the retailer to rely on the wholesaler to fulfill orders more reliably, which is consistent with our hypothesis.
} 
economies of scale to reduce the costs of order processing, picking and packing and hence make inventory ownership more attractive.

Hypothesis 4. Inventory ownership will be positively associated with firm's revenues.

A second part of this hypothesis concerns gross margins. We hypothesize that a firm operating in an industry characterized by high relative gross margins is more likely to accumulate the cash necessary to recoup fixed investments than a firm operating in an industry with smaller margins.

Hypothesis 5. Inventory ownership will be positively associated with the relative gross margin.

Similar to our previous two hypotheses, a firm that has existed for a longer time period is in a better position to recoup fixed investments since more assets have been accumulated. Further support for the same argument comes from the observation that for many Internet start-ups initial capital is a constraint, thus making investment into expensive fulfillment capabilities less feasible. However, after enough time has passed for a company to prove its business model, more funding becomes available and the firm may decide to invest in inventory in order to increase its margin. This advantage of older firms may also be reflected in the lower interest rates that these firms might obtain due to their higher credibility with financial institutions. These arguments lead to our next hypothesis.

Hypothesis 6. Inventory ownership will be positively associated with firm age.

\footnotetext{
${ }^{6}$ If a firm makes an investment into fulfillment capabilities using venture capital money rather than proceeds from their own operation, we still argue that the amount of money that a venture capital firm invests will strongly depend on the profitability of the industry in which this firm operates.
} 


\subsection{Product characteristics}

Some products naturally lend themselves to distribution through drop-shipping while others can effectively be stocked internally. For example, large and heavy products incur significant shipping and handling costs every time they are transported, thus reducing the gross margin. Since the drop-shipping channel avoids the extra cost of shipping the product from the wholesaler to the retailer, it is economical to distribute large and heavy products through the drop-shipping channel. In addition, large and heavy products are expensive to hold in inventory since they occupy a lot of warehousing space and require more handling. Notice that holding costs are incurred by the retailer in the traditional channel and by the wholesaler in the dropshipping channel. Hence, for products characterized by large size and weight, retailers should prefer the drop-shipping channel.

Hypothesis 7. Inventory ownership will be negatively associated with product weight/size.

The second part of this line of argument concerns product obsolescence. A retailer of groceries or flowers may have products that become obsolete daily. Naturally, holding such products in inventory is costly when demand is uncertain. On the other hand, jewelry may actually appreciate in value over time. Obsolescence is equivalent to incurring holding cost for a product and hence, similar to Hypothesis 7, higher obsolescence should translate into a higher likelihood of adopting the drop-shipping channel by the retailer.

Hypothesis 8. Inventory ownership will be negatively associated with product's rate of obsolescence. 


\section{Research Design, Sample Description, Variable Definition}

\subsection{Research Design and Sample Description}

To test our hypotheses about supply chain choice, we use a cross-sectional sample from a population of publicly traded Internet retailers operating between the start of Internet retailing (approximately 1994) and 2002. ${ }^{7}$ The advantage of a cross-sectional sample as opposed to a longitudinal study is that we expect to see more variation in decisions across companies than changes within companies across time. The cross-sectional design also eases data gathering requirements, as companies often do not maintain accurate archival records for our variables of interest. The cross-sectional design does present some difficulties when gathering data for bankrupt companies. For these companies, data were gathered in late 2001 and early 2002, but respondents were asked to provide data on the last year of viable operation.

Our sample is limited to the public domain in order to gather the financial information necessary to test our expectations about economic outcomes. Public companies tend to be larger, more tightly monitored, and better capitalized than non-public companies. Combining several sources of data containing lists of all Internet companies identified a list of potential sample firms. Sources include: EDGAR, the Securities and Exchange Commission site listing all publicly traded companies; BizRate.com, an e-commerce site that rates Internet retailers; Industry Standard, an Internet magazine that publishes lists of publicly traded Internet companies; and Yahoo Finance, an Internet site that provides financial fundamentals for all publicly traded companies. From these sources, we identified 187 publicly traded Internet companies, 63 of which qualified under our criteria as Internet retailers. To qualify as such, a

\footnotetext{
${ }^{7}$ Note that our data collection effort occurs outside of the Internet bubble (late 2000 - early 2001) so that our results should be generalizable beyond this unique time period; this remains to be verified in the future.
} 
firm needed to have the sale of physical goods as a primary means for obtaining revenue (accounting for above $33 \%$ of all revenues ${ }^{8}$ ). Companies delivering digitized goods, which were previously predominantly delivered physically, were excluded (i.e. ticket companies and music companies now delivering electronic tickets and MP3 files). We conducted interviews, examined web-sites and examined public financial records to complete our questionnaire. 55 companies responded favorably to the questionnaire resulting in 53 usable surveys, giving us an overall usable response rate of $84.1 \%$. Depending upon assumptions of the Internet retailing market size, we believe these companies account for $50-70 \%$ of all retailing revenue on the web (which was around \$40B in 2002 according to the US Census). When available, financial data were obtained from COMPUSTAT tapes; otherwise financial data were obtained from annual report information and 10-K filings to the Securities and Exchange Commission.

\subsection{Variable Definition}

In this section, we describe the variables used as constructs in our analyses. Table 1 reports descriptive statistics on each of the variables, including mean, standard deviation, and $10^{\text {th }}, 50^{\text {th }}$ and $90^{\text {th }}$ percentiles.

\section{Dependent Variable:}

Inventory Ownership: We classify a firm as having integrated inventory and web interface using an indicator variable. Inventory ownership takes a value of 1 if over $50 \%$ of a firm's sales come from its own inventory and 0 otherwise. ${ }^{9} 64 \%$ of the firms in the sample primarily rely on

\footnotetext{
${ }^{8}$ Almost all Internet firms either had no connection with physical goods or were clearly in retailing. Hence, changing this threshold to some other number would not have impacted our sample.

${ }^{9}$ In practice, it is sometimes the case that firms will both own inventory and use drop-shipping arrangements such that some portion of sales is filled from firm-owned inventory and the remaining portion is filled from outside inventories. The choice to use a dichotomous variable instead of a more continuous variable such as percent of sales from own inventory was made necessary when, during pilot testing of the survey, respondents would not or could not provide estimates of the percentage of sales filled from their own inventory. While less precise than continuous
} 
owning inventory, while $36 \%$ primarily rely on drop-shipping. These results are similar to results reported by PriceWaterhouse Coopers [3], who reported that in 2000, 30.6\% of all Internet retailers (both publicly traded and private) relied primarily on drop-shipping to fulfill their orders.

\section{Independent Variables:}

We measure some of the independent variables (namely, firm age, firm revenues, product variety, weight/size, and obsolescence) using firm-specific data obtained either through public records or through questionnaires. The remaining variables (namely, relative gross margin, number of retailers and demand uncertainty) are measured for the firm's industry. We measure relative gross margin and demand uncertainty at the industry level to avoid potential endogeneity problems with the inventory investment decision. Number of retailers is an industry level measure by nature. Unless otherwise noted, we estimated variables at the industry level by taking an average in the primary industry of activity as defined by the company using a six digit North American Industry Code (NAICS). Firms in our sample fall into 16 different NAICS industry classifications. For demand uncertainty and relative gross margin, data were gathered for a ten-year period prior to 1995 for all firms in the industry using COMPUSTAT. This time period was selected because it immediately preceded the launch of Internet operation by

variables, a dichotomous variable has been commonly used to represent firm investments in supply chain assets in the vertical integration literature (see Anderson and Schmittlein [1984] as an example). Long [1997] suggests that using a dichotomous variable to represent an unmeasured continuous variable is neither uncommon nor inappropriate. To provide some validity to the use of a dichotomous variable, we examined the average days of inventory (Average Inventory/Cost of Goods Sold) for firms during our time period. For those classified as dropshipping, the median \# of day in inventory was 0 , with $70 \%$ of all firms reporting no inventory. For those classified as owning inventory the median \# of days was 85 with $100 \%$ of all firms reporting some level of inventory. The use of days of inventory as an independent variable is problematic. For many of our hypotheses, the association between days of inventory and the variable is not monotonic. Take demand uncertainty as an example. As demand uncertainty increases theory suggests that days in inventory would also increase (Cachon and Terwiesch [2004]). However, as demand uncertainty hits extremes, we expect to see firms choose to drop-ship at which point the days of inventory becomes 0 . 
companies in our sample and hence represented data that these companies could reasonably use to make their decisions.

Product Variety: We use the number of brands offered by a retailer as a proxy for product variety. Ideally, we would measure the number of products carried or SKUs (stock-keeping units). However, many companies could not provide such a measure. To check the validity of our measure, we examined a sub-sample of Internet retailers where we could verify the brands and products carried. We note a strong positive and significant correlation between the two measures $(r=0.56, p<0.01)$. This is consistent with studies of other industries in which alternative measures of variety are correlated with the number of end products (Randall et al. [1998]). The average number of brands offered by firms in our sample is 807 .

Demand Uncertainty: We use the coefficient of variation of demand in each firm's industry as a measure of demand uncertainty. The data are annual data adjusted for price. MacMillan et al. [1986] used a similar statistical measure of uncertainty. We use the coefficient of variation rather than standard deviation in order to adjust the scale of demand uncertainty (that is measured at the industry level) to the size of the industry. The average coefficient of variation of demand is $0.21 .^{10}$

Number of Retailers: For our empirical specification, we calculate the ratio of retailers to wholesalers at the industry level and use it as a proxy for the number of retailers that each wholesaler serves. Data on both retailers and wholesalers come from the 1990 Census of retailers and wholesalers. We calculate the ratio of retailers to wholesalers by collecting the number of retailers and wholesalers in the primary SIC code for each company. The average

\footnotetext{
${ }^{10}$ In analysis, we also examined several other measures of demand uncertainty calculated using quarter and annual data that were both raw and price-adjusted. These measures yielded coefficients that were below conventional significance cutoffs with respect to the demand uncertainty measures. Results of all other variables still hold when
} 
retailer to wholesaler ratio is $9.06 .{ }^{11}$ In the analysis, we find no statistically significant association with the ratio of retailers to wholesalers. Our model in Appendix 1 suggests that this association is not linear, but increases in the square root of the number of retailers. Subsequent results are presented using this measure, which is statistically significant in some tests.

Firm revenues: We use sales to measure revenues. The average firm has $\$ 315$ million in sales. Due to the skewed nature of this measure, we perform subsequent analyses using the natural logarithm of firm sales. We verified that all but one retailer (which we excluded) in our sample recognized revenues based on the Gross figure. Hence, it appears that accounting rules were used consistently across our sample.

Relative Gross Margin: We measure relative gross margin at the industry level as described above. The average as well as median industry margin is $29 \%$.

Firm Age: We measure firm age in quarters. We use quarters (rather than years) to provide some variance in age due to the short history of Internet retailing. The average firm age is 35 quarters or about 9 years.

Product Weight/Size: We measured product size/weight by asking company personnel to place the majority of their product sales on the following scale: 1-small (CDs, books), 2-small to medium (personal computers), 3-medium (furniture), 4-large (automobiles). Average product size/weight is 1.75 .

Obsolescence: We measured obsolescence risk by asking company personnel to rate on average how frequently their products become obsolete on the following scale: 1- daily, 2- weekly, 3-

using alternative measures of demand uncertainty.

${ }^{11} \mathrm{We}$ also calculate a retailer to wholesaler ratio using a blend of the retailer wholesaler ratios for all SIC codes used by the company. Results do not differ from results using the ratio from the primary SIC code. 
monthly, 4- annually, and 5- never. The mean response rate is 3.0, indicating that most companies report their products go obsolete on a monthly basis.

Table 2 provides Pearson correlation coefficients for the independent variables. We report no problems with colinearity or multi-colinearity.

\section{Results of Hypotheses Tests}

We provide evidence supporting our hypotheses using two types of tests: a univariate test comparing means between companies owning and not owning inventory and a multivariate logistic regression analysis. Table 3 shows the test of mean differences between firms that own inventory and drop-ship. We report significant differences between firms in the sample for product variety, relative gross margin, firm age, and product weight/size. Firms that own inventory tend to sell fewer brands (370 brands vs. 1590 brands), participate in industries with higher gross margins (31\% vs 26\%), be older (52 quarters vs. 27 quarters), and sell smaller products (1.53 vs. 2.15$)$. With these univariate tests, we report no significant difference between groups for demand uncertainty, number of retailers, firm sales, and product obsolescence.

Table 4 presents results from a logistic regression model in which ownership of inventory is the dependent variable. The theory in our hypotheses suggests that the product variety offered by a firm is not exogenous to the decision to hold inventory. ${ }^{12}$ In such circumstances, Kennedy [1998] recommends an instrumental variable approach to remove bias from the parameter estimates. We use an instrument similar to Bayus and Putsis [1999], where brands are considered to be a function of brands offered by competitors, firm share, expected market growth, whether

\footnotetext{
${ }^{12}$ Novak and Eppinger [2001] make similar arguments when examining the effect of complexity on vertical integration in the auto industry.
} 
the firm markets its own brand or not, and the average price of products offered. The predicted value resulting from this regression serves as our instrument. ${ }^{13}$

The model in Table 4 has a statistically significant likelihood ratio and a Max Rescaled Rsquared value of 0.77 . In support of hypotheses $1,5,6$, and 7 and consistent with univariate tests, we report a statistically significant negative association between inventory ownership and product variety and product weight/size and a statistically significant positive association between inventory ownership and relative gross margin and firm age. Differing from univariate tests and supporting hypotheses 2 and 3, we report a statistically significant negative association between inventory ownership and demand uncertainty and the number of retailers. Similar to univariate tests, we report no association between inventory ownership and firm sales and inventory ownership and obsolescence. Rerunning these models using firm market share in place of firm demand yields no significant results for the market share variable. Overall, we find full or partial support for 6 of 8 hypotheses.

In the second column of Table 4, we calculate the standardized percent change in the odds of holding inventory (Long [1997]). This allows for some comparison of the magnitude of the effects each variable has on the odds of holding inventory. For example, a standard deviation change in the relative gross margin increases the odds of owning inventory by a $231.2 \%{ }^{14}$ Using this measure to compare effects, it appears that standard deviation changes in relative gross margin and firm age have the strongest positive influence on the odds of owning inventory, while product variety and number of retailers have the strongest negative influence on the odds

\footnotetext{
${ }^{13}$ The resulting $r$-squared value of the regression to form the instrumental variable was 0.66 .

${ }^{14}$ Standardized percent changes are calculated as suggested by Long [1997] as follows. Standardized factor change

$=\exp ($ coefficient estimate $\mathrm{x}$ standard deviation of independent variable)-1 $\mathrm{x} 100$.
} 
of owning inventory. Examination of regression diagnostics including Pearson residuals and deviance residuals showed no influential data points.

\section{Performance implications of inventory choices}

In this section, we examine the performance implications of inventory choices. We explore two alternative views of how the inventory decision affects profits. The first view hypothesizes that one inventory choice is dominant. In other words, either drop-shipping or the traditional channel will lead to better firm performance. The second view is a contingent view hypothesizing that successful performance will be a function of whether or not the firm chooses the inventory structure most appropriate to its particular competitive situation. Like much recent literature in operations strategy, this hypothesis assumes that high performance comes from the alignment or fit of complementary assets (Milgrom and Roberts [1990], Bozarth and Edwards [1997], Nath and Sudharshan [1994] and, Randall and Ulrich [2001]).

To test the second view, that performance is associated with the fit of the inventory investment decision, Donaldson [2001] identifies several key methodological issues relevant to our situation. First, a performance measure should be reliable and measured after decisions determining fit. Following this suggestion, we use firm bankruptcy as our measure of firm performance. Bankruptcy substantially lags the decision to invest in inventory capabilities. ${ }^{15}$ Further, we believe it to be the most reliable measure of performance given that in our sample of Internet firms we observe profitability measures to be highly volatile. Bankruptcy takes a value of 1 if the company declared bankruptcy during the time of study from 1995 to 2002 and 0

\footnotetext{
${ }^{15}$ In our sample, we noted few cases in which firms had shifted substantially from the initial decision to hold inventory or drop-ship. In other words, a firm would choose an inventory strategy and in general maintain the strategy through our period of study. One noted exception to this rule was Amazon.com. Early in the time period they changed from a drop-shipping strategy to an inventory ownership strategy.
} 
otherwise. Bankruptcies were regularly reported in the Internet magazine Industry Standard and on industry websites. 11 of 53 or $21 \%$ of the firms declared bankruptcy during the time of study. ${ }^{16}$

Second, the measure of fit should be reliable. We use a common and reliable method that determines fit empirically (see Pennings [1987] and Ittner et al. [2003] as examples). Fit, or more appropriately misfit, is determined by the residual from the logistic regression reported in Table 4 and is defined as follows:

$$
\text { MISFIT }=\left\{\begin{array}{l}
1-\text { predicted probability if own inventory } \\
\text { else, predicted probability }
\end{array} .\right.
$$

We also square our MISFIT measure, resulting in MISFIT ${ }^{2}$. By squaring the measure, we exaggerate the distance of those firms making more inappropriate decisions. We expect our measures of MISFIT to be positively associated with bankruptcy. An underlying assumption with empirically derived fit models is that the predictive model of fit reported in Table 4 is a reasonable benchmark to judge fit. This raises the question as to whether bankrupt firms should be included in the initial regression model which determines fit. One might argue that bankrupt firms have clearly not made appropriate choices and should not be included in the regression model that determines fit. On the other hand, firms may make appropriate inventory choices, but still go bankrupt due to other decisions. In this case, they should be included in the regression model that determines fit. We calculate our MISFIT variables based on both views. One

\footnotetext{
${ }^{16}$ Note that two firms in our sample reported being on the verge of bankruptcy and were acquired days before a formal announcement of bankruptcy. These firms were coded as having declared bankruptcy.
} 
measure is based on the entire sample of firms. A second measure is based only on regression results from surviving firms. ${ }^{17}$

Third, other factors associated with firm performance should be included as control variables. In our model, we control for several factors commonly associated with bankruptcy including market share, Altman's Z score (a measure of financial distress), and order of entry to the industry. Market share is defined as the firm's market share at the end of the study or at the time of bankruptcy. We expect larger firms to go bankrupt at a lower rate than smaller firms.

While researchers have not arrived at a conclusive measure of financial distress (Mossman et al. [1998]), we use a commonly cited measure, Altman's Z-score, which was developed to predict corporate bankruptcy using a weighted combination of several financial ratios (Altman [1993]). For non-manufacturing firms, Altman's Z-score $(\mathrm{Z})$ is calculated as

$$
\begin{gathered}
Z=6.56(\text { WorkingCapital } / \text { TotalAssets })+3.26(\text { RetainedEarnings/ } / \text { TotalAssets })+ \\
6.72(\text { EarningsBeforeIncomeTaxes/TotalAssets })+1.05(\text { MarketValueof Equity } / \text { BookValueof Debt })
\end{gathered}
$$

We measure Altman's Z-score at the time a firm goes public (time of first public financial statements). ${ }^{18}$ We select this time period because for a firm making an improper inventory decision, we expect the firm's financial performance to deteriorate due to that decision. If we use the Altman's Z-score at the year of bankruptcy as a control, we face a potential colinearity problem by capturing all the effect of the poor decision with the Z-score rather than in our

\footnotetext{
${ }^{17}$ We note that the analysis using surviving firms resulted in quasi partial separation. Allison [1999] suggests this may be caused by model over specification. In our case this problem is caused by the obsolescence variable. In keeping with Allison [1999], we removed this variable from the model using only surviving firms.

${ }^{18}$ At the time of initial public offering (IPO), a firm is required to disclose its financial position for the year of IPO and for several preceding years. In all cases, we use the earliest publicly reported financial information. On average, this information was disclosed for the year following the founding of the companies.
} 
alignment measure. ${ }^{19}$ The Z-score is measured such that a high Z-score represents financial viability. We expect bankruptcy to be negatively correlated with Z-score. ${ }^{20}$ Finally, we measure entry order as the rank of entry into the industry. Studies in population ecology find a positive relation between the order of market entry and bankruptcy, with firms entering later in the industry going bankrupt more quickly (Carrol and Hannan [1989]). At this point, we recognize that there may be other correlated omitted variables, a problem commonly found in the literature.

To analyze bankruptcy of companies in our sample, we use a common survival analysis technique known as the Cox proportional hazards model (Cox [1972]). Like most survival analysis techniques, the Cox model accommodates right censoring of the data (Allison [1995], Kiefer [1988]). The Cox model estimates a partial likelihood ratio that assumes that the hazard rate between observations is proportional over time even though the underlying hazard rate for all observations does vary with time. Practically, this assumption means that time-dependent variables that do not vary across observations are eliminated from the estimation procedure as long as the time of origin is selected carefully. ${ }^{21}$ We use calendar time, as opposed to firm time, as the point of origin and adjust for firms that have late entry into the data set. We choose calendar time because of the macro-economic influences that accompanied the Internet era. This allows us to interpret the proportional hazards as the proportional hazards between observations at a given point in calendar history. It also legitimizes the elimination of the macro-economic

\footnotetext{
${ }^{19}$ Models using Altman's Z-score at the time of bankruptcy do not significantly alter results, but provide less explanatory power than those using Altman's Z-score at the time of IPO.

${ }^{20}$ Altman [1993] suggests that the Z-score not be used as a continuous variable, but that several cutoffs be used to make predictions on bankruptcy. We also formulate dichotomous variables based on cutoffs suggested by Altman, a median cutoff, and a first quartile cutoff. For example, if a firm has a Z-score below the median, then we would predict bankruptcy and the Z-score measure would take a value of 1 , otherwise 0 . Results of these analyses do not differ from reported results.

${ }^{21}$ For example, macro-economic factors that vary by time but not by observation would be eliminated from the estimation procedure.
} 
variables from the estimation procedure. We use the exact method to handle tied data. The general hazard function estimated, $h_{i}(t)$, for the $i$ th observation at time $\mathrm{t}$ is represented by:

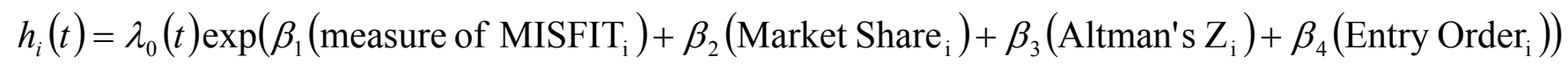
Here $t$ is the time to bankruptcy and $\lambda_{0}(t)$ is the baseline hazard rate which cancels in the partial likelihood estimation procedure.

Table 5 shows results of the Cox proportional hazard models. The likelihood ratio tests indicate that all models are significant except the model in column I. R-squared values range from $12.09 \%$ to $28.24 \%$. Each column shows an alternative measure for inventory ownership or MISFIT. In column I, we report no association between the indicator variable for inventory ownership and the hazard of bankruptcy, implying that simple inventory choice is not associated with performance in our sample. In columns II and III, we show results of models using MISFIT measures derived from a predictive model using all firms. We report no significant association between MISFIT and the hazard of bankruptcy, but a positive and significant association between (MISFIT) ${ }^{2}$ and the hazard of bankruptcy. In columns IV and V, we show the results of models using MISFIT measures derived from a predictive model using only surviving firms. Consistent with expectations, we report a positive significant association between MISFIT and $(\text { MISFIT) })^{2}$. It is interesting to note that the significance of results for our misfit measures is much stronger in the models in which only surviving firms are used in the predictive model.

As for our control variables, we note that in every case the entry order variable is positive and significant, indicating higher bankruptcy rates for later entrants. We note in column IV and $\mathrm{V}$ a positive significant coefficient for Altman's Z-score. This is contrary to predictions that higher Z-scores lead to a lower hazard of bankruptcy. We report no association between market 
share and the hazard of bankruptcy. To test robustness, we examined deviance residuals and found no influential observations.

\section{Discussion of implications and limitations}

This empirical study examines the factors associated with the choice to own fulfillment capabilities or to drop-ship products among Internet retailers. There exist numerous empirical studies that analyze firms on the Internet from marketing and information system perspectives. To the best of our knowledge, our work is one of the first to empirically analyze operational issues of Internet companies, namely supply chain choice. We find that relative gross margin, firm age, product variety, demand uncertainty, ratio of retailers to wholesalers, and product size are all significant factors in the decision to own inventory. In the analysis, we do not see any association between firm demand and the decision to hold inventory. This may be an artifact of our sample because we chose publicly traded companies that tend to be larger than private companies, effectively excluding smaller retailers from the analysis.

We find support for the idea that firms making appropriate decisions consistent with our analysis are less likely to go bankrupt than outlier firms. This finding emphasizes the strategic importance of thoroughly understanding the inventory decision. We are cautious about forecasting the future of firms we classify as outliers, but have not yet gone bankrupt. Often a firm will be in a temporary state of misalignment having put assets in place for the future. However, if a strategy fails, the decision is costly and the investment is difficult to reverse. For example, one of the companies we studied went bankrupt in the process of trying to change its inventory strategy to a strategy that our model predicted would be more aligned with market and strategy conditions. From a recent interview with founders of Spun.com (a private retailer that is 
not a part of our sample), we found that the company is currently in transition from dropshipping operations to inventory ownership.

A possible limitation of our study arises from the fact that we focus on two extreme versions of inventory ownership; namely, the firm either drop-ships or owns inventory. In practice companies may employ hybrid strategies (see Netessine and Rudi [2004b] for an extensive treatment of this issue). An example would be a situation in which the company owns the most popular products but drop-ships slow-moving items or uses drop-shipping as a back-up mechanism once the company runs out of inventory. Our use of a dichotomous variable has the potential to weaken statistical results. One other limitation of our study is that we are unable to measure the number of wholesalers able to drop-ship products (i.e., those that have invested in drop-shipping capabilities). It is possible that this number varies by industry and/or over time. Difficulty accounting for this effect is dictated by the lack of data.

It is entirely possible that there are other explanatory variables that were omitted from our study. One example is the geographical spread of customers. A large wholesaler may have multiple warehouses and hence might be able to serve geographically spread customers more cheaply. However, information on the geographical spread is hard to obtain. It is also possible that the competitor's channel choice has an effect, although we do not have a clear prediction of the direction of this effect. Longer lead times (similar to demand uncertainty) are likely to favor drop-shipping but they are hard to measure and moreover, lead-times will probably vary by product and by supplier. Company's cost of capital is another factor since it will affect fixed costs but we believe that it is largely attended to through the incorporation of firm's age: older firms are typically able to borrow more cheaply. Also, contractual arrangements may affect the 
decision to invest in fulfillment capabilities. Future research may uncover other drivers of Internet retailers' decision to invest into fulfillment capabilities.

Our study was performed at a high strategic level. Future empirical work may be performed to examine operational questions surrounding how to achieve effective vertical integration or disintegration in the Internet environment and comparative performance of companies with different supply chain structures. Internet retailers typically must invest heavily in software that ties front-end store operation with back-end fulfillment. In the case of virtual inventories such investment may be particularly important since the front-end of one company has to be aligned with fulfillment performed by another company.

\section{References}

[1] "The American dream gone bad". The Industry Standard, August 28, 2000, pages 71-73.

[2] "Cheap tricks". Forbes, February 21, 2000, page 116.

[3] "The state of e-retailing 2000". The supplement to Eretailing World.

[4] "Fulfillment Nets". 2000. Commerce Infrastructure, Vol.4, Jupiter Communications.

[5] "Online retailers will turn to drop-shippers as almost half lose money on shipping and handling". February 8, 2001. Press Release, Jupiter Media Metrix.

Allison, P. 1999. Logistic regression using the SAS system: Theory and Application, SAS Institute Inc., Cary NC.

Altman, E. 1993. Corporate financial distress and bankruptcy: A complete guide to predicting and avoiding distress and profiting from bankruptcy. John Wiley \& Sons, Canada.

Anderson, E. and D. C. Schmittlein. 1984. Integration of the sales force: An empirical investigation. Rand Journal of Economics, Vol.15, 385-395.

Bayus, B.L. and W.P. Putsis. 1999. Product proliferation: An empirical analysis of product line determinants and market outcomes. Marketing Science, Vol.18, 137-153.

Bozarth, C. and S. Edwards. 1997. The impact of market requirements focus and manufacturing characteristics focus on plant performance. Journal of Operations Management, Vol.15, 161180.

Cachon, G.P. and C. Terwiesch. 2004. Matching supply with demand: An introduction to operations management. McGraw-Hill, New York, NY. 
Carrol, G. and M. Hannan. 1989. Density delay in the evolution of organizational populations: A model and five empirical tests. Administrative Science Quarterly, Vol.34, 411-430.

Cox, D. 1972. Regression models and life tables. Journal of the Royal Statistical Society, Vol.34, 187-220.

Dinlersozy E.M. and H. Li. 2003. Shipping news: An analysis of Internet retailers' shipping strategies, Working Paper, University of Houston.

Donaldson, L. 2001. The contingency theory of organizations. Sage Publications, CA.

Eppen, G. 1979. Effects of centralization on expected costs in a multi-location newsboy problem. Management Science, Vol.25, 498-501.

Evans, P. and T.S. Wurster. 2000. Getting real about virtual commerce. HBR OnPoint product 4525.

Ghemawat, P. and B. Baird. 1998. Leadership online: Barnes \& Noble vs. Amazon.com (A). Case Study, HBS.

Ghosh, S. 1998. Making business sense of the Internet. Harvard Business Review, March-April, 126-135.

Gujarati, D. 1995. Basic econometrics. McGraw-Hill, New York, NY

Hendricks, K.B. and V. Singhal. 2003. An empirical analysis of the effect of supply chain disruptions on operating performance. Working Paper, Georgia Institute of Technology.

Ittner, C., Larcker, D. and T. Randall. 2003. The Implications of strategic performance measurement in financial services firms. Accounting Organizations and Society, OctoberNovember. 715-741.

Johnson, E.M. 2002a. Garden.com - at the end of the runway. Case Study, Dartmouth College.

Johnson, E.M. 2002b. Chempoint and Yantra: extraprise management in the specialty chemical industry. Case Study, Dartmouth College.

Johnson, E.M. and S. Whang. 2002. E-business and supply chain management: an overview and framework. Production and Operations Management, Vol.11, 413-423.

Kennedy, P. 1998. A guide to econometrics, $4^{\text {th }}$ edition. MIT Press, Boston, MA.

Kiefer, N. 1998. Economic duration data and hazard functions. Journal of Economic Literature, June, 646-679.

Lieberman, M.B. and R. Dhawan. 2000. Assessing the resource base of US and Japanese auto producers: A stochastic frontier production function approach. Working Paper, UCLA.

Long, J. S. 1997. Regression models for categorical and limited dependent variables. Sage Publications, CA.

MacMillan, I.C., D.C. Hambrick and J.M. Pennings. 1986. Uncertainty reduction and the threat of supplier retaliation -2 views of the backward integration decision. Organizational Studies, Vol.7, 263-278. 
Milgrom, P. and J. Roberts. 1990. The economics of modern manufacturing: Technology, strategy and organization. American Economic Review, Vol.80, 511-528.

Mossman, C., G. Bell, G.L. Swartz and H. Turtle. 1998. An empirical comparison of bankruptcy models. The Financial Review, Vol.33, 35-54.

Nath, D. and D. Sudharshan. 1994. Measuring strategy coherence through patterns of strategic choices. Strategic Management Journal, Vol.15, 43-61.

Netessine S. and N. Rudi. 2004a. Supply chain structures on the Internet and the role of marketing-operations interaction. Forthcoming in "Handbook of supply chain analysis in the ebusiness era" by Simchi-Levi et al., editors. Kluwer Academic Publishers.

Netessine S. and N. Rudi. 2004b. Supply chain choice on the Internet. Working Paper, University of Pennsylvania. Available at http://www.netessine.com.

Novak, S. and S. D. Eppinger. 2001. Sourcing by design: Product complexity and the supply chain. Management Science, Vol.47, 189-204.

Pennings, J.M. 1987. Structural contingency theory: A multivariate test. Organization Studies, Vol.8, 223-240.

Ramdas, K. 2003. Managing product variety: An integrative review and research directions. Production and Operations Management, Vol.12, 79-101.

Randall, T., S. Netessine and N. Rudi. 2002. Should you take the virtual fulfillment path? Supply Chain Management Review, November-December, 54-58.

Randall, T., K. Ulrich and D. Reibstein. 1998. Brand equity and vertical product line extent. Marketing Science, Vol.17, 356-379.

Randall, T. and K. Ulrich. 2001. Product variety, supply chain structure, and firm performance: Analysis of the U.S. bicycle industry. Management Science, Vol.47, 1588-1604.

Roth, A. and W.E. Jackson III. 1995. Strategic determinants of service quality and performance: Evidence from the banking industry. Management Science, Vol.41, 1720-1733.

Scheel, N.T. 1990. Drop-shipping as a marketing function. Greenwood Publishing Group.

Silver, E.A., D.F. Pyke and R. Peterson. 1998. Inventory management and production planning and scheduling. John Wiley and Sons.

Simchi-Levi, D., S.D. Wu and Z.M. Shen. 2004. Handbook of supply chain analysis in the ebusiness era, Kluwer Academic Publishers.

Singh, P., Groenevelt, H. and N. Rudi. 2003. Product variety and supply chain structure. Working Paper, University of Rochester.

van Ryzin, G. and S. Mahajan. 1999. Retail inventories and consumer choice. In "Quantitative models for supply chain management", S. Tayur, R. Ganeshan and M. Magazine, editors, Kluwer Academic Publishers. 


\begin{tabular}{lccccc}
\hline & Table 1: Descriptive Statistics (N=53) \\
\hline & \# Own & \# Drop Ship & & & \\
Inventory Ownership & 34 & 19 & \multicolumn{4}{c}{ Percentiles } \\
& Mean & Std. Dev. & 10 th & 50 th & 90 th \\
\hline Product Variety (Brands) & 807.87 & 1856.29 & 25 & 490 & 901 \\
Demand Uncertainty (Industry Coefficient of Demand Variation) & 0.21 & 0.04 & 0.18 & 0.22 & 0.23 \\
\# of Retailers (Retailer Wholesaler Ratio) & 9.06 & 7.46 & 1.78 & 7.78 & 17.02 \\
Firm Sales & 315.51 & 865.82 & 0.02 & 20.08 & 812.41 \\
Relative Gross Margin & 0.29 & 0.08 & 0.19 & 0.29 & 0.39 \\
Firm Age & 35.53 & 21.85 & 11.00 & 27.00 & 79.00 \\
Product Weight/Size & 1.75 & 0.89 & 1.00 & 1.00 & 3.00 \\
Product Obsolescence & 3.00 & 0.85 & 2.00 & 3.00 & 4.00 \\
\hline
\end{tabular}

Brands: Number of brands carried by the company.

Industry Coefficient of Demand Variation: standard deviation of industry sales over 10 years/industry sales since 1985.

Retailer Wholesaler Ratio: Retailers / Wholesalers.

Firm sales: Sales at time of initial public offering.

Relative Gross Margin: Average gross margin for a firm's industry over 10 years prior to firm entry.

Firm Age: Age of firm measured in quarters.

Product Weight/Size: 1 to 4 scale. 1-small (CDs, books), 2-small to medium (personal computers), 3-medium (furniture), 4-large (automobiles).

Product obsolescence: 1 to 5 scale. 1-daily, 2-weekly, 3-monthly, 4-annually, 5-never.

Table 2: Correlation Among Independent Variables

$(\mathrm{N}=53)$

\begin{tabular}{|c|c|c|c|c|c|c|c|c|}
\hline & 1. & 2. & 3. & 4. & 5. & 6. & 7. & 8. \\
\hline 1. Product Variety (Brands) & 1.00 & & & & & & & \\
\hline $\begin{array}{l}\text { 2. Demand Uncertainty (Industry } \\
\text { Coefficient of Demand Variation) }\end{array}$ & $-0.24 *$ & 1.00 & & & & & & \\
\hline $\begin{array}{l}\text { 3. Square Root \# Retailers (Retailer } \\
\text { Wholesaler Ratio) }\end{array}$ & 0.13 & -0.06 & 1.00 & & & & & \\
\hline 4. Ln(Firm Sales) & 0.04 & 0.19 & -0.21 & 1.00 & & & & \\
\hline 5. Relative Gross Margin & -0.17 & 0.18 & $0.33 * *$ & -0.01 & 1.00 & & & \\
\hline 6. Firm Age & -0.19 & 0.18 & -0.18 & $0.35 * * *$ & -0.04 & 1.00 & & \\
\hline 7. Product Weight/Size & $0.27 *$ & -0.03 & $-0.30 * *$ & 0.21 & $-0.37 * * *$ & 0.21 & 1.00 & \\
\hline 8. Produce obsolescence & -0.23 & 0.14 & -0.01 & 0.01 & 0.22 & -0.15 & 0.05 & 1.00 \\
\hline
\end{tabular}

$* * *, * * * \mathrm{p}$-value significant at $\mathrm{p}<.01, .05$ and .10 respectively. 
Table 3: Tests of Mean Differences for Firms Owning Inventory and Drop-shipping $(\mathrm{N}=53)$

\begin{tabular}{|c|c|c|c|c|}
\hline \multicolumn{5}{|c|}{$(\mathrm{N}=53)$} \\
\hline \multirow[b]{2}{*}{ Product Variety (Brands) } & $\begin{array}{c}\text { Own } \\
\text { Inventory }\end{array}$ & \multicolumn{3}{|c|}{$\begin{array}{l}\text { P-value for test } \\
\text { Drop Ship Difference of mean difference }\end{array}$} \\
\hline & 370.72 & 1590.13 & $(1219.41)$ & 0.02 \\
\hline Demand Uncertainty (Industry Coefficient of Demand & & & & \\
\hline Variation) & 0.21 & 0.21 & 0.00 & 0.98 \\
\hline Square Root \# of Retailers (Retailer Wholesaler Ratio) & 2.83 & 2.76 & -0.07 & 0.83 \\
\hline Ln(Firm Sales) & 2.44 & 1.14 & 1.10 & 0.36 \\
\hline Relative Gross Margin & 0.31 & 0.26 & 0.05 & 0.01 \\
\hline Firm Age & 40.16 & 27.25 & 12.91 & 0.04 \\
\hline Product Weight/Size & 1.53 & 2.15 & -0.62 & 0.01 \\
\hline Product obsolescence & 2.91 & 3.15 & -0.24 & 0.32 \\
\hline
\end{tabular}

Table 4: Logistic Regression Model of Inventory Ownership $(\mathrm{N}=53$, Wald Chi-Square Statistics in brackets)

\begin{tabular}{|c|c|c|}
\hline & Coefficient & $\begin{array}{l}\text { Standardized } \\
\text { Change }\end{array}$ \\
\hline \multirow[t]{2}{*}{ Intercept } & $17.47 * *$ & - \\
\hline & {$[4.72]$} & \\
\hline \multirow[t]{2}{*}{ Product Variety (Brands Instrumental Variable) } & $-0.01 * * *$ & $-99.9 \%$ \\
\hline & {$[6.73]$} & \\
\hline \multirow[t]{2}{*}{ Demand Uncertainty (Industry Coefficient of Demand Variation) } & $-62.51 * *$ & $-91.8 \%$ \\
\hline & [4.29] & \\
\hline \multirow{3}{*}{$\begin{array}{l}\text { Square Root \# of Retailers (Square Root of Retailer Wholesaler } \\
\text { Ratio) }\end{array}$} & & \\
\hline & $-0.91 *$ & $-99.9 \%$ \\
\hline & [3.52] & \\
\hline \multirow[t]{2}{*}{ Firm Sales } & -0.02 & - \\
\hline & {$[0.06]$} & \\
\hline \multirow[t]{2}{*}{ Relative Gross Margin } & $14.97 *$ & $231.2 \%$ \\
\hline & {$[3.01]$} & \\
\hline \multirow[t]{2}{*}{ Firm Age } & $0.05 *$ & $198.1 \%$ \\
\hline & [3.62] & \\
\hline \multirow[t]{2}{*}{ Product Weight/Size } & $-1.38 * *$ & $-70.7 \%$ \\
\hline & {$[4.85]$} & \\
\hline \multirow[t]{2}{*}{ Product obsolescence } & -0.11 & - \\
\hline & {$[0.04]$} & \\
\hline Max Rescaled R-Squared & 0.77 & \\
\hline Likelihood Ratio Test & $35.49 * * *$ & \\
\hline
\end{tabular}

$* * *, * * * \mathrm{p}$-value significant at $\mathrm{p}<.01, .05$ and .10 respectively. 
Table 5: Association between Bankruptcy and Alignment of Inventory Choice $(\mathrm{N}=53$, Wald Chi-square statistics in brackets)

\begin{tabular}{|c|c|c|c|c|c|}
\hline \multirow[t]{2}{*}{ Dependent Variable: Bankruptcy } & \multirow[b]{2}{*}{ Model I } & \multicolumn{2}{|c|}{ All firms in Predictive Model } & \multicolumn{2}{|c|}{$\begin{array}{c}\text { Surviving Firms in Predictive } \\
\text { Model }\end{array}$} \\
\hline & & Model II & Model III & Model IV & Model V \\
\hline Own Inventory & $\begin{array}{c}0.09 \\
{[0.02]}\end{array}$ & - & - & - & - \\
\hline MISFIT & - & $\begin{array}{c}1.61 \\
{[1.75]}\end{array}$ & - & $\begin{array}{c}2.72 * * * \\
{[9.99]}\end{array}$ & - \\
\hline$(\text { MISFIT })^{2}$ & - & - & $\begin{array}{c}2.50^{* *} \\
{[3.98]}\end{array}$ & - & $\begin{array}{c}2.83 * * * \\
{[11.15]}\end{array}$ \\
\hline Market Share & $\begin{array}{l}-28.28 \\
{[0.76]}\end{array}$ & $\begin{array}{l}-21.08 \\
{[0.48]}\end{array}$ & $\begin{array}{l}-23.12 \\
{[0.47]}\end{array}$ & $\begin{array}{l}-17.36 \\
{[0.32]}\end{array}$ & $\begin{array}{l}-18.28 \\
{[0.37]}\end{array}$ \\
\hline Altman's Z-Score & $\begin{array}{c}0.06 \\
{[1.46]}\end{array}$ & $\begin{array}{c}0.06 \\
{[1.96]}\end{array}$ & $\begin{array}{c}0.07 \\
{[2.03]}\end{array}$ & $\begin{array}{l}0.11^{*} \\
{[3.29]}\end{array}$ & $\begin{array}{l}0.12^{*} \\
{[3.79]}\end{array}$ \\
\hline Entry Order & $\begin{array}{l}0.05^{*} \\
{[3.45]}\end{array}$ & $\begin{array}{l}0.04^{*} \\
{[3.29]}\end{array}$ & $\begin{array}{l}0.05^{*} \\
{[3.74]}\end{array}$ & $\begin{array}{l}0.07 * * \\
{[5.88]}\end{array}$ & $\begin{array}{l}0.07 * * \\
{[6.04]}\end{array}$ \\
\hline R-squared & $12.09 \%$ & $14.67 \%$ & $16.91 \%$ & $27.03 \%$ & $28.24 \%$ \\
\hline Likelihood Ratio Test & 6.83 & $8.41 *$ & $9.82 * *$ & $16.70^{* * *}$ & $17.59 * * *$ \\
\hline
\end{tabular}

$* * *, * *, *$ significant at $\mathrm{p}<.01, \mathrm{p}<.05$, and $\mathrm{p}<.10$

\section{Appendix A. Analytical model of the Internet channel.}

In this appendix we present a stylized analytical model that can be used to derive predictions regarding the impact of product and environmental characteristics on the decision regarding inventory ownership. This model incorporates many parameters of the environment in which Internet retailers operate and is based on more elaborate models of Netessine and Rudi [2004b] and Singh et al. [2003], which can be consulted for details.

Variables pertinent to the traditional and drop-shipping channels are denoted by superscripts $\mathrm{T}$ and $\mathrm{D}$, correspondingly. Time is subdivided into $M$ periods corresponding to inventory replenishment decisions with $t=1$ when the retailer begins operation and $t=M$ at the end of our study or at the end of the retailer's operation due to bankruptcy, merger, etc. We use the Multinomial Logit (MNL) model to formalize the consumer choice process (see van Ryzin and Mahajan [1999] and Singh et al. [2003] for similar approaches). An assortment of products that a retailer sells is represented by continuous variable $v$, $0<v<1$ where $v=1$ corresponds to all possible products. The assortment is fixed over the whole time period, which is satisfactory for our purposes. In some cases assortments change over time, which can be incorporated without affecting our hypotheses. In period $t$, total consumer demand at the retailer is assumed to be approximately Normal with mean $\mu_{t}$ and standard deviation $\sigma_{t}$ and demands are independent across retailers. Correlated demands can be easily incorporated in the model, but correlation is hard to estimate empirically so we omit it.

Denote by $p(j)$ customers' preference for product $j$ in the variety, and order products via decreasing preference. Let $p_{0}$ denote the no-purchase option. Then, according to the MNL model, for a given variety choice $v$, in period $t$ each retailer faces total demand that is Normal with the following parameters ${ }^{22}$ :

\footnotetext{
${ }^{22}$ It is assumed here that, if demand doubles, the variance of demand doubles as well. Using some other assumption here would have had no impact (see Singh et al. [2003], van Ryzin and Mahajan [1999]). All that matters in our setting is that the
} 


$$
\bar{\mu}_{t}=\mu_{t} \frac{\int_{0}^{v} p(j) d j}{p_{0}+\int_{0}^{v} p(j) d j}=\mu_{t} f(v), \bar{\sigma}_{t}=\sigma_{t} \mu_{t}^{1 / 2} \frac{\int_{0}^{v} p^{1 / 2}(j) d j}{\left(p_{0}+\int_{0}^{v} p(j) d j\right)^{1 / 2}}=\sigma_{t} \mu_{t}^{1 / 2} g(v) .
$$

Functions $f(v)$ and $g(v)$ are essentially probabilities that the customer will purchase from the retailer with product variety $v$. Denote fixed costs associated with establishing the operational infrastructure by $F$ (fixed costs differ by channel). Then each retailer's total profit can be written as

$$
\begin{gathered}
\Pi^{T}=\sum_{t=1}^{M} \int_{0}^{v^{T}} \pi_{t}^{T}(j) d j-F^{T}, \\
\Pi^{D}=\sum_{t=1}^{M} \int_{0}^{v^{D}} \pi_{t}^{D}(j) d j-F^{D},
\end{gathered}
$$

where $\pi_{t}(j)$ represents period $t$ profit from product variant $j$. The expression for $\pi_{t}(j)$ is further formalized as follows. We assume that there are $n$ identical retailers in the channel, all buying from the same wholesaler. The symmetry assumption is not essential to the model but it makes expressions much more transparent. Each product is sold at unit-price $r$, is purchased from the wholesaler at unit-cost $w$ in the traditional channel and at unit-cost $w+\delta$ in the drop-shipping channel. We do not explicitly model transportation costs/revenues as they are assumed to be incorporated into the wholesale/retail prices. Transportation costs can be made explicit (see Netessine and Rudi [2004b]). Inventory is managed using an order-up-to model with zero lead time. Non-zero lead times can be incorporated and can have the potential to influence channel choice if different product categories have sufficiently different lead times. We assume that unsatisfied demand is lost and unsold inventory is carried over to the next period, incurring holding cost $h$. The setting with demand backordering can be similarly modeled. Given these assumptions, when the order-up-to quantity is $q$, the retailer's per-period profit in the traditional channel is given by

$$
\begin{aligned}
\pi_{t}^{T}(j) & =(r-w) \min \left(d_{t}, q_{t}\right)-h\left(d_{t}-q_{t}\right)^{+} \\
= & (r-w+h) \min \left(d_{t}, q_{t}\right)-h q_{t} .
\end{aligned}
$$

Let $z_{t}^{T}=\left(q_{t}^{T}-\mu_{t}\right) / \sigma_{t}$. Using this convention and denoting the standard Normal Loss function by $L(z)$ we obtain

$$
\pi_{t}^{T}(j)=(r-w) \mu_{t}-\sigma_{t}\left((r-w) L\left(z_{t}^{T}\right)+h z_{t}^{T}\right) .
$$

In the drop-shipping channel, the manufacturer uses the order-up-to quantity $Q_{t}$, which is selected based on the total demand from all retailers (which is Normal with mean $n \mu$ and standard deviation $\sigma \sqrt{n}$ ). Assuming that in expectation all retailers receive the same share of inventory (and hence the same share of profit), we obtain

$$
\pi_{t}^{D}=\frac{(r-w-\delta)}{n} \min \left(\sum_{i=1}^{n} d_{t i}, Q_{t}\right) .
$$

Let $z_{t}^{D}=\left(Q_{t}-n \mu_{t}\right) /\left(\sigma_{t} \sqrt{n}\right)$ so that the retailer's profit can be re-written as follows:

$$
\pi_{t}^{D}(j)=(r-w-\delta)\left(\mu_{t}-\sigma_{t} L\left(z_{t}^{D}\right) / \sqrt{n}\right) .
$$


Finally, we obtain expressions for the multi-period profit functions in two channels:

$$
\begin{gathered}
\Pi^{T}=\sum_{t=1}^{M}\left[(r-w) \mu_{t} f\left(v_{T}\right)-\sigma_{t} \mu_{t}^{\beta} g\left(v_{T}\right)\left((r-w) L\left(z_{t}^{T}\right)+h z_{t}^{T}\right)\right]-F^{T}, \\
\Pi^{D}=\sum_{t=1}^{M}\left[(r-w-\delta)\left(\mu_{t} f\left(v_{D}\right)-\sigma_{t} \mu_{t}^{\beta} g\left(v_{D}\right) L\left(z_{t}^{D}\right) / \sqrt{n}\right)\right]-F^{D} .
\end{gathered}
$$

These profit expressions can be used to obtain empirical predictions regarding channel choice with problem parameters as independent variables. That is, we can observe the effect of problem parameters on the retailer who selects between two channels by choosing the higher of (4) and (5), which can be used to hypothesize that the same behavior should be observed in practice.

Hypothesis 1: product variety. Higher product variety $v$ leads to higher revenues in either channel because function $f(v)$ is increasing in product variety $v$ (see (1)). However, higher product variety increases costs as well: this is captured by function $g(v)$, which is increasing in $v$. The effect of risk pooling is reflected by the fact that total cost $\sigma \mu^{\beta} g\left(v_{D}\right) L\left(z_{D}\right)$ in the drop-shipping channel is divided by the square root of the number of retailers, $\sqrt{n}$. Hence, we can expect that the detrimental effect of higher product variety is smaller in the drop-shipping channel, as Singh et al. [2003] demonstrate formally.

Hypothesis 2: demand uncertainty. Retailers' profit in both the traditional and the drop-shipping channels is decreasing in demand variability. However, in the drop-shipping supply chain, the wholesaler is able to mitigate the detrimental effects of demand variability due to the benefits of risk pooling. Similar to the previous hypothesis, this effect is observed from (5) where cost per retailer is reduced by the factor $\sqrt{n}$ : while the retailer in the traditional channel faces demand with standard deviation proportional to $\sigma$, the retailer in the drop-shipping channel experiences (indirectly) demand with standard deviation proportional to $\sigma / \sqrt{n}$. Hence, higher demand uncertainty will have a large detrimental impact in the traditional channel.

Hypothesis 3: number of retailers. Note that, as the number of retailers $n$ increases, each retailer's profit in the traditional channel (4) is unaffected. On the other hand, in the drop-shipping channel (5) each retailer's cost of demand uncertainty is decreasing with $n$. Hence, higher $n$ will make drop-shipping preferred.

Hypotheses 4 and 5: revenues and gross margins. To distill the impact of problem parameters, note that the revenue parts of (4) and (5) can be written as:

$$
\begin{aligned}
& (r-w) \mu_{t} f\left(v_{T}\right)=\frac{(r-w)}{r} r \mu_{t} f\left(v_{T}\right)=G_{T} R_{t}\left(v_{T}\right), \\
& (r-w-\delta) \mu_{t} f\left(v_{D}\right)=\frac{(r-w-\delta)}{r} r \mu_{t} f\left(v_{D}\right)=G_{D} R_{t}\left(v_{D}\right),
\end{aligned}
$$

where $G$ denotes the relative gross margin and $R$ denotes the single-period revenue. Hence, our model suggests that larger firms (in terms of having larger revenue stream $R$ and in terms of larger gross margins $G$ ) will choose to invest in fixed costs because they will accumulate cash more quickly, while smaller firms will choose to drop-ship in order to avoid large fixed costs.

Hypotheses 7 and 8: product weight/size and obsolescence. Profit in the traditional channel is decreasing in the inventory holding cost $h$, making large and heavy products with high level of obsolescence suitable for the drop-shipping channel. 